\title{
On the contribution of $f$ electrons to the quadratic hyperpolarizability: the case of Lanthanide Terpyridyl Complexes
}

\author{
Fatima Ibersiene ${ }^{a}$, Camille Latouche $^{b}$, Claudine Katan $^{c}$, Abdou Boucekkine $^{\text {tc }}$
}

\author{
a. Laboratoire de Thermodynamique et Modélisation Moléculaire, Faculté de Chimie, USTHB, 16111 Bab Ezzouar Alger, \\ Algeria. \\ b. Institut des Matériaux Jean Rouxel (IMN), Université de Nantes, CNRS, 2 rue de la Houssinière, BP 32229, 44322 Nantes \\ cedex 3, France. \\ c. Université de Rennes, Institut des Sciences Chimiques de Rennes (ISCR), UMR 6226 CNRS, Campus de Beaulieu, 35042 \\ Rennes Cedex, France. \\ $\dagger$ abdou.boucekkine@univ-rennes1.fr \\ Electronic Supplementary Information (ESI) available: optimized geometries and simulated UV-visible spectra. See DOI: \\ $10.1039 / \mathrm{x} 0 \mathrm{xx} 00000 \mathrm{x}$
}

\begin{abstract}
Over the last decades, trivalent lanthanide ions $\left(\operatorname{Ln}^{3+}\right)$ have gained much attention due to their peculiar luminescence, which opened the way to a broad range of applications, from medical diagnostic to lasers. Their impact on nonlinear optical (NLO) properties also attracted interest, especially in the framework of lanthanide complexes. Several experimental studies demonstrated that the quadratic hyperpolarizability varies with the number of $4 \mathrm{f}-$ electrons, with a stronger effect on dipolar than octupolar components. The main interpretation put forward to explain the observed trends relied on the polarizable character of the $4 \mathrm{f}$ electrons. We report here a first step towards understanding the role of $4 \mathrm{f}$-electrons in NLO responses, considering a series of dipolar terpyridyl-trinitro lanthanide complexes $\operatorname{LLn}\left(\mathrm{NO}_{3}\right)_{3}(\mathrm{Ln}=$ $\mathrm{Gd}, \mathrm{Dy}, \mathrm{Yb}, \mathrm{Lu}$ as well as La and $\mathrm{Y}$; L=terpyridil-like ligand). Using DFT and TD-DFT we investigate their linear and non-linear optical properties. Consistently with earlier experimental findings, simulated UV-visible spectra show minor changes by varying $\boldsymbol{L}$. The same holds for dipole moments and polarizabilities, whereas the nature of the lanthanide affects hyperpolarizabilities. It is shown that the observed changes are not a direct effect of the 4felectrons that behave like core electrons.
\end{abstract}

\section{Introduction}

In the past decades, transition metal and lanthanide complexes have been widely investigated, especially for their strong ability to be luminescent ${ }^{1}$ but also as candidates for new nonlinear optical (NLO) active materials. ${ }^{2-14}$ In 2006, Le Bozec, Maury and coll. ${ }^{7}$ who synthesized and characterized the first dipolar lanthanide terpyridyl complex family $\operatorname{LLn}\left(\mathrm{NO}_{3}\right)_{3}(\mathrm{~L}=$ 4,4"'dimethyl,4'-

$(N, N$ dimethylaminophenyl)2,2',6',2'terpyridine $L n=L a, G d$, Dy and $\mathrm{Yb}$ ) found that their first order hyper-polarizabilities ( $\beta$ ), measured using Harmonic Light Scattering (HLS) experiments, increase with the number of $4 \mathrm{f}$ electrons, whereas their UVvisible absorption spectra remain almost unchanged. Such behavior is rather surprising. A similar trend of the secondorder NLO response was observed by Valero et al. for various lanthanide (Ln) complexes [ $\mathrm{Ln}(\mathrm{hfac}) 3$ (diglyme) $] \quad(\mathrm{hfac}=$ hexafluoroacetylacetonate; diglyme = bis(2-methoxyethyl)ethe ${ }^{8}$ and Gulino et al. for trinuclear $\left[\mathrm{Ln}\left(\mathrm{NO}_{3}\right)_{3}(\mathrm{CuL})_{2}\right]$ complexes ( $\mathrm{Ln}=\mathrm{La}, \mathrm{Ce}, \mathrm{Sm}, \mathrm{Eu}$ and $\mathrm{Er}, \mathrm{L}=\mathrm{N}, \mathrm{N}^{\prime}-1,3$-propylenbis(salicylideniminato). ${ }^{9}$ In these studies, both HLS and EFISH techniques were used to measure $\beta$. This helped to establish the respective influence of dipolar and octupolar contributions to the quadratic hyperpolarizability, which was shown to be dominated by the octupolar part whereas the dipolar one is significantly influenced by the number of $4 \mathrm{f}$ electrons. From these studies, it was concluded that $\beta$ undergoes a systematic increase with the number of $f$ electrons, and the main explanation put forward by several authors was an unexpected polarizable character of the $4 \mathrm{f}$ electrons in the Ln complexes. ${ }^{10}$ Furthermore, Tanner, Wong and coll. ${ }^{11}$ first examined an extended series of dipolar Ln complexes of trans-cinnamic acid, followed by Parker and coll. ${ }^{12}$ with a series of ninecoordinate chiral triazacyclononane complexes having both dipolar and octupolar contributions. Whereas both these extensive investigations are almost fully consistent with previously reported trends, they reveal that $\beta$ reaches a maximum around the center of the whole Ln series. More recently, a series of octupolar phtalocyanine-based Ln complexes ( $\mathrm{Ln}=\mathrm{Nd}$, Eu, Dy, Lu compared to $\mathrm{Y}$ ) also revealed a strong dependence of $\beta_{H L S}$ on the number of $4 f$ electrons with similar trends for neutral, reduced and oxidized species. ${ }^{14}$ These results call into question the interpretation of the firstorder hyperpolarizability dependence on the number of $4 \mathrm{f}$ electrons in terms of polarization of the f electrons.

This study aims to provide a first step towards a better understanding of the structure-property relationship between the $4 \mathrm{f}$-electron shell and quadratic hyperpolarizability of Ln complexes. We start with a series of dipolar complexes to restrict complexity and chose the terpyridyl-trinitro lanthanide complexes $\mathrm{LLn}\left(\mathrm{NO}_{3}\right)_{3}$ for which experimental data are available

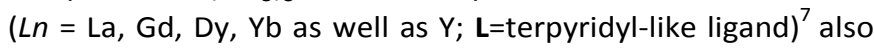
including $L n=L u$. Based on DFT and TD-DFT computations with the PBEO functional (see computational details), ${ }^{15-24}$ we shall successively examine their structural, electronic and linear optical properties and finally their NLO responses. 


\section{Results and discussion}

\section{Molecular structure}

The general structure of the complexes under investigation is displayed in Figure 1. All complexes exhibit a typical dipolar push-pull structure, with $\mathrm{N}$-dimethyl aniline as the donating group and the terpyridine moiety as the main electron withdrawing group. Even so X-ray diffraction data are available for two complexes, we optimized the structure of each complex in the solvent $\left(\mathrm{CH}_{2} \mathrm{Cl}_{2}\right)$ to afford computed data relevant to available experimental photophysical data. ${ }^{7}$ Table 1 reports selected structural data derived from these optimized geometries that are compared with X-ray diffraction data. ${ }^{7}$ Since we compare optimized geometries in solution $\left(\mathrm{CH}_{2} \mathrm{Cl}_{2}\right)$ to solid state ones, the overall agreement between the $\mathrm{X}$-ray data and the computed geometrical parameters is good. In particular, the computed dihedral angles and the X-ray ones are expected to be different. Indeed, (i) the dihedral angle $\Theta$ between the terpyridyl and the $\mathrm{N}$-dimethyl aniline moieties is computed to be $c a .20^{\circ}-30^{\circ}$ lower in solution than in the solid state, (ii) the NCCN dihedral angles are larger in solution than in solid state for $\mathrm{LGd}\left(\mathrm{NO}_{3}\right)_{3}$ whereas the reversed situation is observed in $\mathrm{LY}\left(\mathrm{NO}_{3}\right)_{3}$. This clearly evidences steric effects and intermolecular interactions induced by the molecular packing in the crystalline solid state. Besides, the Gd-O and Gd-N bond lengths are higher than the $\mathrm{Y}-\mathrm{O}$ and $\mathrm{Y}-\mathrm{N}$, consistently with the larger ionic radius of $\mathrm{Gd}^{3+}$ as compared to $\mathrm{Y}^{3+}$.

\section{Electronic structure and UV-visible spectra}

Table 2 summarizes computed (Figure S2) and measured ${ }^{7}$ UVvis data, namely the wavelengths of the two first main absorption bands and corresponding calculated oscillator

Table 1 Selected structural data of $\operatorname{LGd}\left(\mathrm{NO}_{3}\right)_{3}$ and $\mathrm{LY}\left(\mathrm{NO}_{3}\right)_{3}$ complexes with $\mathbf{L}=$ terpyridyl-like ligand, from computed optimized geometries and X-ray data. ${ }^{7}$ Distances are given in $\AA ̊$ and angles in degrees.

\begin{tabular}{|c|c|c|c|c|c|}
\hline $\operatorname{Ln}^{3+} / \mathbf{M}^{3+}$ ion & & $\mathbf{G d}^{3+}$ & $\begin{array}{c}\mathbf{G d}^{3+} \\
\text { X-ray }\end{array}$ & $\mathrm{Y}^{3+}$ & $\begin{array}{c}\mathrm{Y}^{3+} \\
\mathrm{X} \text {-ray }\end{array}$ \\
\hline \multirow[t]{6}{*}{ M-O } & O40-М39 & 2.486 & $2.503(8)$ & 2.433 & $2.454(4)$ \\
\hline & O45-М39 & 2.476 & $2.485(7)$ & 2.473 & $2.465(4)$ \\
\hline & O46-M39 & 2.493 & $2.460(9)$ & 2.470 & $2.431(4)$ \\
\hline & O53-М39 & 2.504 & $2.446(9)$ & 2.482 & $2.376(4)$ \\
\hline & O51-M39 & 2.473 & $2.437(7)$ & 2.477 & $2.369(4)$ \\
\hline & O54-M39 & 2.499 & $2.459(8)$ & 2.498 & $2.428(4)$ \\
\hline M-N(central) & N18-M39 & 2.475 & $2.445(9)$ & 2.424 & $2.365(9)$ \\
\hline \multirow[t]{2}{*}{$\begin{array}{l}a v . \mathrm{M}- \\
\mathrm{N} \text { (dist.) }\end{array}$} & N10-M39 & 2.631 & $2.551(8)$ & 2.610 & $2.503(4)$ \\
\hline & N23-M39 & 2.653 & $2.573(8)$ & 2.605 & $2.513(4)$ \\
\hline Cpy-Cph & C15-C31 & 1.483 & $1.516(16)$ & 1.484 & $1.489(7)$ \\
\hline N-Ph & N37-C34 & 1.376 & $1.384(15)$ & 1.378 & $1.381(7)$ \\
\hline \multirow[t]{4}{*}{ C-C (interPy) } & C9-C14 & 1.486 & $1.499(14)$ & 1.484 & $1.490(6)$ \\
\hline & C17-C19 & 1.486 & $1.537(15)$ & 1.484 & $1.493(6)$ \\
\hline & C14-N18-C17 & 119.2 & - & 119.3 & - \\
\hline & C15-C31-C36 & 121.2 & - & 121.2 & - \\
\hline \multirow[t]{2}{*}{ NCCN } & N23-C19-C17-N18 & 20.6 & 15.0 & 19.8 & 2.0 \\
\hline & N10-C9-C14-N18 & 19.8 & 10.0 & 19.5 & 10.5 \\
\hline$\Theta$ & C13-C15-C31-C32 & 58.8 & 79.2 & 61.0 & 95.0 \\
\hline
\end{tabular}

21

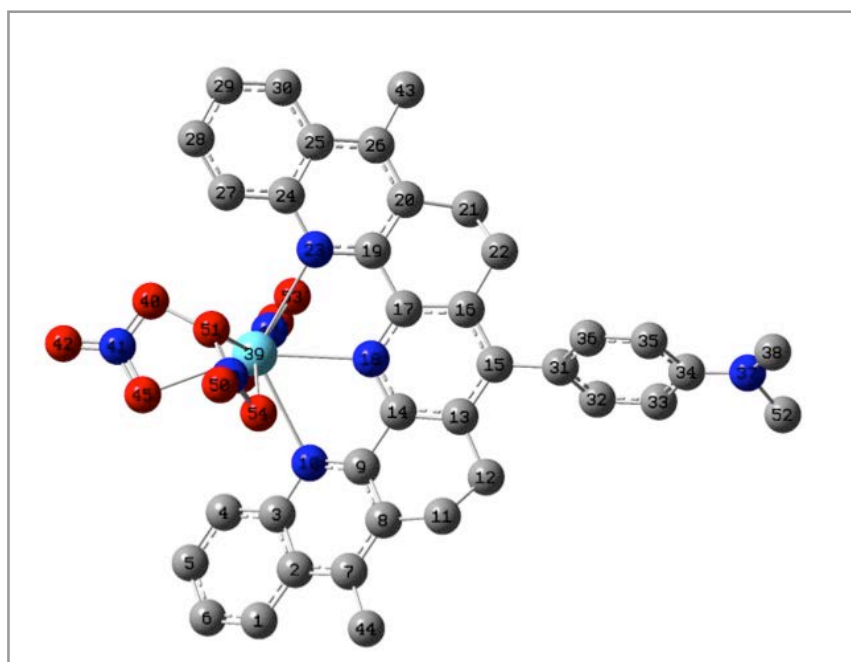

Fig. 1 Structure of the $\mathbf{L L n}\left(\mathrm{NO}_{3}\right)_{3}$ complex (L=terpyridyl-like ligand) with atomic numbering, $L n$ is number 39 . Color code is turquoise blue for lanthanide, red for oxygen, grey for carbon and royal blue for nitrogen. Hydrogen atoms have been omitted for clarity.

strengths $f$ as well as experimental molar extinction coefficients $\varepsilon$. The main transitions leading to the computed absorption bands are also given with relevant molecular orbitals (MO) plotted in Figure 2. Overall, the computed photophysical data show good agreement with experimental findings. We find a small systematic overestimation of the highest wavelength absorption band corresponding to $c a .0 .15$ $\mathrm{eV}$ for all complexes. The second very intense absorption band at shorter wavelengths is well reproduced by the simulations, with a systematic small underestimation of the wavelengths corresponding to $c a$. $0.20 \mathrm{eV}$. Noteworthy, such differences are usual given the level of theory used to compute excited states, in this instance the solvation model and the lack of vibronic contributions. Besides, when using other DFT exchange-correlation functionals, i.e. B3LYP, ${ }^{21}$ CAM-B3LYP ${ }^{22}$ and $M 062 X,{ }^{23}$ comparison between the simulated and experimental UV-visible spectra worsened, in particular with CAM-B3LYP and M062X that led to large underestimation of the absorption energies of $c a .1 \mathrm{eV}$ (Supplementary Table S2). The MOs involved in the transitions reported in Table 2 are depicted in Figure 2 for $\operatorname{LY}\left(\mathrm{NO}_{3}\right)_{3}$ and $\mathrm{LGd}\left(\mathrm{NO}_{3}\right)_{3}$. The frontier MOs are similar for all complexes. It is interesting to note that the $\alpha$ and $\beta$ frontier MOs are identical. The lowest energy transitions are dominated by an electronic transition from the highest occupied $\mathrm{MO}$ (HOMO) to the lowest unoccupied MO (LUMO), whereas the second absorption band mainly involves HOMO-1 and LUMO. For the two $\operatorname{LY}\left(\mathrm{NO}_{3}\right)_{3}$ and $\operatorname{LGd}\left(\mathrm{NO}_{3}\right)_{3}$ complexes, the atomic orbital composition of these MOs as well as their energies are almost identical since they do not involve the metal ion. As expected for the ligands used in these complexes, the HOMO is dominated by the $\mathrm{N}$ dimethylaminophenyl donating moiety whereas the LUMO is mainly localized on the terpyridyl ligand. 
A more detailed frontier MO diagram of this complex is given in Figure S1. Interestingly the SOMO and SOMO-1 of the complexes are localized on the terpyridine ligand as well as the LUMO+1, so that the absorption bands observed at $c a .390 \mathrm{~nm}$ correspond to intra-ligand excitation and not to an inter-ligand charge transfer one, like the band at $c a .450 \mathrm{~nm}$. The LUMO+2, which contributes to the higher lying band also visible in the experimental spectra ( $c a .325 \mathrm{~nm}$ ) is different from the other unoccupied MOs since it is localized on the electron withdrawing nitro groups.

Table 2 Computed and experimental ${ }^{7}$ photophysical data of $\operatorname{LLn}\left(\mathrm{NO}_{3}\right)_{3}$ complexes, with $\mathrm{Ln}=\mathrm{La}, \mathrm{Gd}$, Dy, Yb, Lu as well as $\mathrm{Y}$ and with $\mathrm{L}=$ terpyridyl-like ligand, in $\mathrm{CH}_{2} \mathrm{Cl}_{2}$.

\begin{tabular}{|c|c|c|c|c|c|}
\hline $\begin{array}{l}\operatorname{Ln}^{3+} / M^{3+} \text { ion } \\
\left(4 f^{\mathrm{n}}\right) \\
\text { spin multiplicity }\end{array}$ & $\begin{array}{r}\lambda_{\max } \\
\mathrm{nm} \\
\text { calc. }\end{array}$ & $\begin{array}{l}f \\
\text { calc. }\end{array}$ & $\begin{array}{l}\text { Main } \\
\text { transitions } \\
\text { (weight) }^{\mathrm{a}}\end{array}$ & $\begin{array}{l}\lambda_{\max } \\
\mathrm{nm} \\
\text { exp. } \\
7\end{array}$ & $\begin{array}{l}\text { E } \\
\text { L.mol } \\
{ }^{1} \cdot \mathrm{cm}^{-1} \\
\text { exp. }\end{array}$ \\
\hline $\mathrm{Y}^{3+}$ & 480 & 0.18 & $\mathrm{H} \rightarrow \mathrm{L}(99 \%)$ & 454 & 4750 \\
\hline $2 S+1=1$ & 372 & 0.56 & $\mathrm{H}-1 \rightarrow \mathrm{L}(92 \%)$ & 392 & 28900 \\
\hline & 326 & 0.51 & $\mathrm{H}-1 \rightarrow \mathrm{L}+1(77 \%)$ & & \\
\hline $\mathrm{La}^{3+}$ & 475 & 0.17 & $\mathrm{H} \rightarrow \mathrm{L}(99 \%)$ & 453 & 5400 \\
\hline$\left(4 f^{0}\right)$ & 370 & 0.56 & $\mathrm{H}-1 \rightarrow \mathrm{L}((93 \%)$ & 391 & 24500 \\
\hline $2 S+1=1$ & 323 & 0.52 & $\mathrm{H}-1 \rightarrow \mathrm{L}+1(74 \%)$ & & \\
\hline $\begin{array}{l}\mathrm{Gd}^{3+} \\
\left(4 f^{7}\right)\end{array}$ & 476 & 0.19 & $\begin{array}{l}S \alpha \rightarrow L \alpha(100 \%) \\
S \beta \rightarrow L \beta(95 \%)\end{array}$ & 452 & 5800 \\
\hline $2 S+1=8$ & 367 & 0.56 & $\begin{array}{l}S-1 \alpha \rightarrow L \alpha(93 \%) \\
\text { S- } 1 \beta \rightarrow L \beta(91 \%) \\
\text { - } 1 \beta \rightarrow L+1 \beta(42 \%) \\
S \beta \rightarrow L+2 \beta(31 \%) \\
S \alpha \rightarrow L+2 \alpha(23 \%) \\
\end{array}$ & 393 & 26900 \\
\hline $\begin{array}{l}\mathrm{Dy}^{3+} \\
\left(4 \mathrm{f}^{9}\right)\end{array}$ & 482 & 0.19 & $\begin{array}{l}S \alpha \rightarrow L \alpha(100 \%) \\
S \beta \rightarrow L \beta(97 \%)\end{array}$ & 450 & 5400 \\
\hline $2 S+1=6$ & 370 & 0.51 & $\begin{array}{l}S-1 \alpha \rightarrow L \alpha(85 \%) \\
S-1 \beta \rightarrow L \beta(84 \%) \\
S \alpha \rightarrow L+2 \alpha(52 \%) \\
S-1 \alpha \rightarrow L+1 \alpha(43 \%) \\
S \beta \rightarrow L+4 \beta(32 \%)\end{array}$ & 394 & 26700 \\
\hline $\begin{array}{l}Y^{3+} \\
\left(4 f^{13}\right) \\
2 S+1=2\end{array}$ & 472 & 0.22 & $\begin{array}{l}S \beta \rightarrow L+1 \beta(84 \%) \\
S-3 \alpha \rightarrow L \alpha(26 \%) \\
S-3 \alpha \rightarrow L+1 \alpha(23 \%)\end{array}$ & 452 & 5150 \\
\hline & 376 & 0.43 & $\begin{array}{l}S-1 \beta \rightarrow L+1 \beta(85 \%) \\
S-1 \alpha \rightarrow L \alpha(75.9 \%)\end{array}$ & 394 & 28850 \\
\hline $\begin{array}{l}\mathbf{L u}^{3+} \\
\left(4 \mathrm{f}^{14}\right) \\
2 \mathrm{~S}+1=1\end{array}$ & $\begin{array}{l}482 \\
373 \\
327\end{array}$ & $\begin{array}{l}0.17 \\
0.56 \\
0.51\end{array}$ & $\begin{array}{l}H \rightarrow L(99 \%) \\
H-1 \rightarrow L(92 \%) \\
H-1 \rightarrow L(77 \%)\end{array}$ & - & - \\
\hline
\end{tabular}

Next, we inspect position of the $4 \mathrm{f}$ lanthanide orbitals. As expected they behave as core orbitals in the complexes. For instance, in the case of $\mathrm{LGd}\left(\mathrm{NO}_{3}\right)_{3}$ the $4 \mathrm{f}$ atomic orbitals $(\mathrm{AO})$ are very low lying in energy (HOMO-73 to HOMO-79), at ca. $8.5 \mathrm{eV}$ below the HOMO. For $\mathrm{Dy}, \mathrm{Yb}$ and Lu complexes the $4 \mathrm{f}$ orbitals are located 7.5, 6.4 and $7.1 \mathrm{eV}$ below the HOMO, respectively. Moreover, these $4 \mathrm{f} \mathrm{AOs}$ exhibit no mixing with the ligand orbitals. This is confirmed by considering the $4 \mathrm{f}$ electrons as core electrons, incorporating them into each pseudopotential (4f in-core calculation) ${ }^{24}$ for the $\mathrm{Gd}^{3+}$, $\mathrm{Dy}^{3+}, \mathrm{Yb}^{3+}$ and $\mathrm{Lu}^{3+}$ ions that possess a non-empty $4 \mathrm{f}$ shell. Moreover, other orbitals namely the $5 \mathrm{~d}$ and $6 \mathrm{~s}$ ones neither contribute to the frontiers MOs of the complexes. The virtual MOs of $\mathrm{LGd}\left(\mathrm{NO}_{3}\right)_{3}$ containing a high contribution of the $4 \mathrm{f} \mathrm{Gd}$ orbitals are rather high in energy. The lowest ones are $\beta$ MOs, namely LUMO+8 to LUMO+14.

\section{NLO properties}

Next, we compute the dynamical hyperpolarizabilities $\beta$ based on the CPHF method ${ }^{20}$ and taking into account the solvent $\left(\mathrm{CH}_{2} \mathrm{Cl}_{2}\right)$. We used the following expression to derive tot from the components of the tensor:

$\beta_{t o t}^{z}=\beta_{x x x}^{z}+\beta_{y y y}^{2}+\beta_{z z z}^{z}+3 \beta_{x y y}^{2}+3 \beta_{x z z}^{z}+3 \beta_{y z z}^{z}+3 \beta_{y x x}^{z}+3 \beta_{z x x}^{z}+3 \beta_{z x x}^{z}+6 \beta_{x y z}^{2}$ This expression is consistent with the measurement of quadratic hyperpolarizabilities using the HLS method ${ }^{25}$ and the $X$ convention for the non-linear tensor. ${ }^{26}$

Interestingly, computed $\beta_{\text {tot }}$ show a remarkable agreement

Table 3 Computed $\beta_{\text {tot }}$ and experimental ${ }^{7} \beta_{\exp }\left(\beta_{\mathrm{HLS}}\right)$ first order dynamical hyperpolarizabilities of $\mathbf{L} \operatorname{Ln}\left(\mathrm{NO}_{3}\right)_{3}$ complexes, with $\mathbf{L n}$ $=\mathrm{La}, \mathrm{Gd}$, Dy, $\mathrm{Yb}, \mathrm{Lu}$ as well as $\mathrm{Y}$ and with $\mathbf{L}=$ terpyridyl-like ligand, in $\mathrm{CH}_{2} \mathrm{Cl}_{2}$ at $\lambda=1907 \mathrm{~nm}$. $4 \mathrm{f}$ electrons are either treated as valence electrons (4f-valence) or incorporated in the pseudopotentials (4f-in-core).

\begin{tabular}{cccc}
\hline $\mathbf{L n}^{3+} / \mathbf{M}^{3+}$ ion & $\begin{array}{c}\beta_{\text {tot }} \\
4 f-\text { valence } \\
10^{-30} \text { esu }\end{array}$ & $\begin{array}{c}\beta_{\text {tot }} \\
4 f-i n-c o r e \\
10^{-30} \text { esu }\end{array}$ & $\begin{array}{c}\beta_{\text {HLS }} \\
\text { exp. } \\
10^{-30} \text { esu }\end{array}$ \\
\hline $\mathrm{Y}^{3+}$ & 232 & - & 191 \\
\hline $\mathrm{La}^{3+}$ & 212 & - & 186 \\
\hline $\mathrm{Gd}^{3+}$ & 239 & 247 & 246 \\
\hline $\mathrm{Dy}^{3+}$ & 253 & 256 & 260 \\
\hline $\mathrm{Yb}^{3+}$ & 242 & 243 & 288 \\
\hline $\mathrm{Lu}^{3+}$ & 226 & 228 & - \\
\hline
\end{tabular}

with experimental values (Table 3). In fact, computed quadratic hyperpolarizabilities follow almost the same trend as the experimental ones, namely they increase with the atomic number of the $\mathrm{Ln}^{3+}$ cation for the considered atomic species. The only discrepancy is that the computed value of the $\mathrm{Yb}$ complex is smaller to that of the Dy complex, which runs counter experimental data, but differences range within experimental standard errors $(15 \%)^{7}$.

Meanwhile, the smaller $\beta_{\text {tot }}$ for $L n=Y b$ as compared to Dy is fully in line with the experimental results reported for a larger extent of lanthanides on two different series of different complexes. ${ }^{11,12}$ Besides, for the lutetium ion, which has the largest number of $4 \mathrm{f}$ electrons, the increase of $\beta$ also collapses in $\mathrm{LLu}\left(\mathrm{NO}_{3}\right)_{3}$. Unfortunately, the quadratic hyperpolarizability of $\mathrm{LLu}\left(\mathrm{NO}_{3}\right)_{3}$ has not been measured experimentally, but, our computed value falls between that of the $\mathrm{La}$ and $\mathrm{Yb}$ complexes, which is again consistent with the trends observed in experimental data obtained on tris(cinnamate) complexes and for triazacyclonoane-based complexes. ${ }^{11,12}$ Thus, our results on $\operatorname{LLn}\left(\mathrm{NO}_{3}\right)_{3}$ are consistent with previously reported observations, ${ }^{11,12}$ namely that the quadratic hyperpolarizability reaches a maximum in the vicinity of the center of the lanthanide series. Then, we further checked the assumption of possible impact of the polarizable character of $4 \mathrm{f}$ electrons. To this end, we also computed the dynamic hyperpolarizabilities $\beta$ using a basis set where the $4 \mathrm{f}$ electrons are incorporated in the pseudopotentials ( $4 \mathrm{f}$ in-core calculations) ${ }^{24}$ for the $\mathrm{Gd}^{3+}$, $\mathrm{Dy}^{3+}, \mathrm{Yb}^{3+}$ and $\mathrm{Lu}^{3+}$ ions, which possess a non-empty $4 \mathrm{f}$ shell. Surprisingly, the trends are the same for both levels of theory with comparable computed $\beta_{\text {tot }}$ values (Table 3 ). This demonstrates the core-like nature of the $4 \mathrm{f}$ electrons (vide 
supra) and that these core electrons affect only marginally the NLO response.

Since the hyperpolarizability depends on the nature of the metal/lanthanide ion, we found interesting to investigate if other molecular electrical properties i.e. ground state dipole moments and polarizabilities exhibit a similar behavior. Interestingly, both the dipole moments $\mu$ and mean isotropic polarizabilities $\left(\alpha_{i s o}\right)$ are almost constant in the series of complexes (Table 4), and the small variations are not in line with changes computed for $\beta_{\text {tot }}$. Thus, the nature of the lanthanide cation has little influence on these properties. In addition, all complexes exhibit also similar excited state dipole moments. Using all the computed values within the two-level model we further checked if the model is capable of providing the correct trend. This is not the case, highlighting contributions stemming from other excitations. Thus, only the higher order responses to the perturbing applied electromagnetic field seem to depend on the nature of the lanthanide ion and the peculiar trend reported for the quadratic hyperpolarizabilities when varying the lanthanide ion cannot be traced back to a direct impact of the $4 \mathrm{f}$-electron shell.

\section{Computational details}

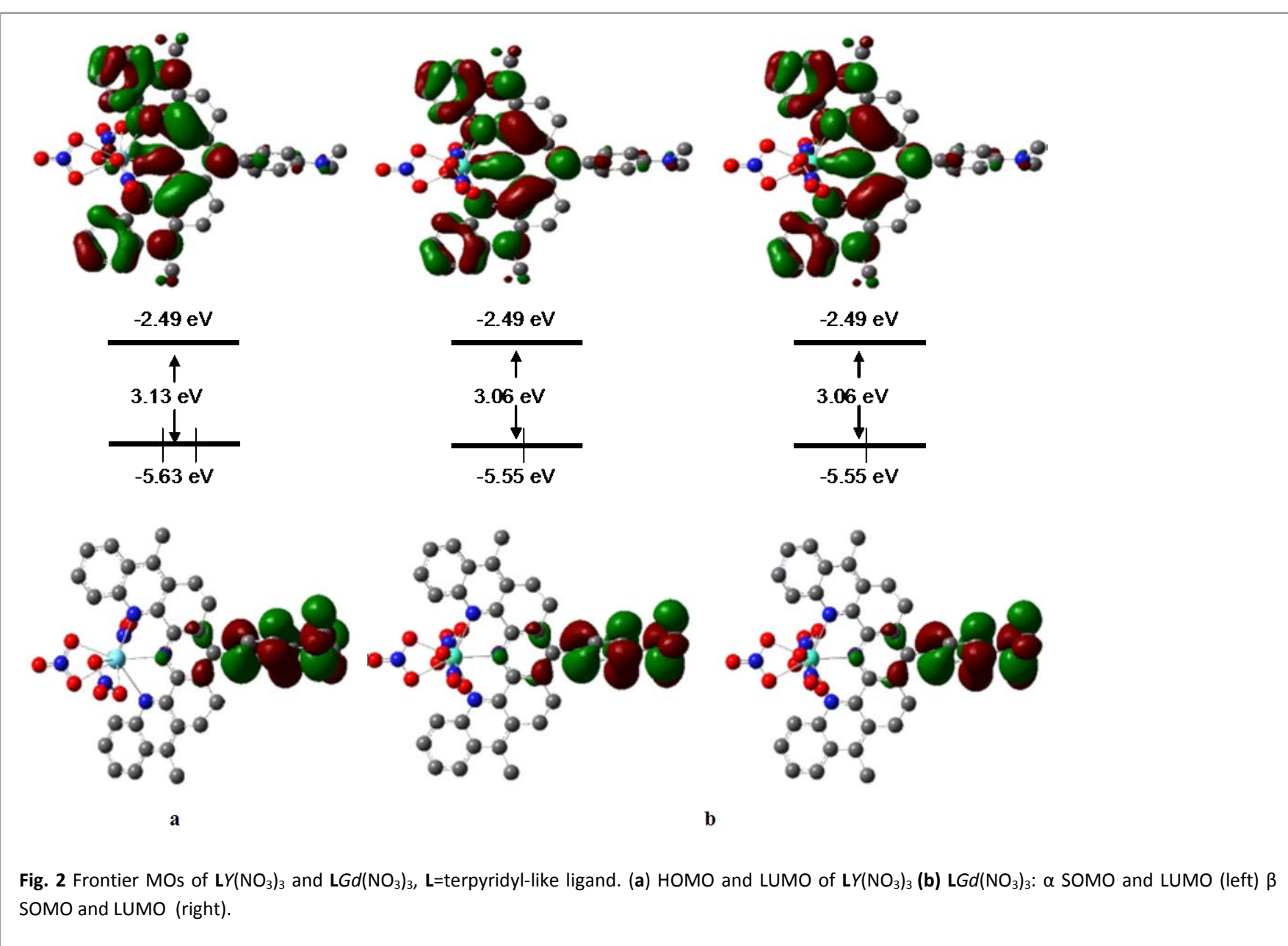

Table 4 Computed dynamic polarizabilities $\alpha_{\text {iso }}$ (at $\lambda=1907 \mathrm{~nm}$ ) and dipole moments $\mu$ of $\mathbf{L} \operatorname{Ln}\left(\mathrm{NO}_{3}\right)_{3}$ complexes, with $\mathrm{Ln}=\mathrm{La}$, $\mathrm{Gd}$, Dy, $\mathrm{Yb}$, Lu as well as $\mathbf{Y}$ and with $\mathbf{L}=$ terpyridyl-like ligand, in $\mathrm{CH}_{2} \mathrm{Cl}_{2}$ at $\lambda=1907 \mathrm{~nm}$. $4 \mathrm{f}$ electrons are either treated as valence electrons (4f-valence) or incorporated in the pseudopotentials (4fin-core).

\begin{tabular}{ccccc}
\hline $\begin{array}{c}\mathbf{L n}^{3+} / \mathbf{M}^{3+} \\
\text { ion }\end{array}$ & $\begin{array}{c}\alpha_{\text {iso }} \\
\text { 4f-valence } \\
10^{-24} \text { esu }\end{array}$ & $\begin{array}{c}\alpha_{\text {iso }} \\
4 f-i n-c o r e \\
10^{-24} \text { esu }\end{array}$ & $\begin{array}{c}\mu \\
4 f-v a l e n c e \\
(D)\end{array}$ & $\begin{array}{c}\mu \\
4 f-i n-c o r e \\
(D)\end{array}$ \\
\hline $\mathrm{Y}^{3+}$ & 126 & - & 27 & - \\
\hline $\mathrm{La}^{3+}$ & 127 & - & 29 & - \\
\hline $\mathrm{Gd}^{3+}$ & 127 & 128 & 27 & 28 \\
\hline $\mathrm{Dy}^{3+}$ & 124 & 125 & 26 & 27 \\
\hline $\mathrm{Yb}^{3+}$ & 126 & 126 & 27 & 27 \\
\hline $\mathrm{Lu}^{3+}$ & 126 & 126 & 26 & 26 \\
\hline
\end{tabular}

The DFT calculations have been performed using the Gaussian09 package. ${ }^{16}$ The geometries of all compounds have been optimized without symmetry constraints using the PBEO functional ${ }^{15}$ and the LANL2DZ ${ }^{17}$ basis set augmented with polarization functions for $\mathrm{C}, \mathrm{N}, \mathrm{O}$, La and $\mathrm{Y}$ only, whereas the Stuttgart RSC 1997 basis set $^{18}$ has been used for the other lanthanide atoms. Other basis sets have been checked, which did not induce any significant alteration of the computed properties and we further assessed that spin-orbit coupling does not qualitatively change the conclusions (details in $\mathrm{SI}$ ). Solvent effects $\left(\mathrm{CH}_{2} \mathrm{Cl}_{2}\right)$ have been taken into account using the 
Polarizable Continuum Model (PCM). ${ }^{19}$ The electronic ground states are singlets for the $Y$, La and Lu complexes whereas the Gd, Dy and Yb species exhibit respectively octet, sextet and doublet spin states, reminding that the electronic configurations of the lanthanide $\mathrm{Ln}^{3+}$ ions are as follows: $\mathrm{La}^{3+}$ $\left(4 f^{0}\right), G^{3+}\left(4 f^{7}\right), D^{3+}\left(4 f^{9}\right), Y b^{3+}\left(4 f^{13}\right)$ and $L u^{3+}\left(4 f^{14}\right)$. Spin contamination was found very low for the open-shell systems. Next, TD-DFT calculations have been performed using the optimized geometries to determine the electronic transitions involved in the excitations and to simulate the absorption spectra (Figure S2). The $\beta$ hyperpolarizabilities have been calculated at the same level of theory using the CPHF time dependent perturbation theory ${ }^{20}$ as implemented in the Gaussian09 package.

\section{Conclusions}

In summary, considering a series of terpyridyl-trinitro lanthanide complexes $\mathrm{LLn}\left(\mathrm{NO}_{3}\right)_{3}$ of dipolar nature we examined the impact of the number of $4 f$ electrons on their linear and nonlinear optical properties. We found that their ground and excited state dipole moments, polarizabilities and absorption spectra change only slightly in the series $L n=Y$, La, $\mathrm{Gd}, \mathrm{Dy}, \mathrm{Yb}$ and Lu. Meanwhile, the dynamic first-order hyperpolarizability $\beta$ undergoes sizeable variations, consistently with earlier experimental findings on these $\operatorname{LLn}\left(\mathrm{NO}_{3}\right)_{3}$ complexes and other lanthanide complexes. Given the range of metal and lanthanide ions considered, our results also suggest that $\beta$ increases with the number of $f$ electrons, but $\beta$ is likely to reach its maximum around Dysprosium. We further inspected possible effect of polarization of the $4 \mathrm{f}$ electrons on computed properties by comparing results obtained when the f-electrons are maintained among the valence electrons with those obtained when they are considered as core electrons. We found out that the $4 \mathrm{f}$ electrons have a core-like nature and do affect only marginally the quadratic hyperpolarizability, thus their unexpected polarizable character is hardly responsible for the observed changes and alternative explanations deserve to be explored in the future.

\section{Conflicts of interest}

There are no conflicts to declare.

\section{Acknowledgements}

This work was granted access to the HPC resources of CINES and IDRIS under the allocation 2016-080649 and 2017-080649 made by GENCI. A.B. and C.L. acknowledge the hospitality of Prof. Vincenzo Barone at SNS Pisa, where part of the present study has been done. COST CM-1006 action is also acknowledged.

\section{Notes and references}

M. H. V. Werts, Sci. Prog., 2005, 88, 101-131.

A. Baccouche, B. Peigné, F. Ibersiene, D. Hammoutène, A. Boutarfaïa, A. Boucekkine, C. Feuvrie, O. Maury, I. Ledoux and H. Le Bozec, J. Phys. Chem. A, 2010, 114, 5429-5438.

L. Ordronneau, V. Aubert, V. Guerchais, A. Boucekkine, H. Le Bozec, A. Singh, I. Ledoux and D. Jacquemin, Chem. - A Eur. J., 2013, 19, 5845-5849.

M. Zaarour, A. Singh, C. Latouche, J. a G. Williams, I. Ledoux-Rak, J. Zyss, A. Boucekkine, H. Le Bozec, V. Guerchais, C. Dragonetti, A. Colombo, D. Roberto and A. Valore, Inorg. Chem., 2013, 52, 7987-7994.

J. Boixel, V. Guerchais, H. Le Bozec, D. Jacquemin, A. Amar, A. Boucekkine, A. Colombo, C. Dragonetti, D. Marinotto, D. Roberto, S. Righetto and R. De Angelis, J. Am. Chem. Soc., 2014, 136, 5367-5375.

A. Colombo, C. Dragonetti, D. Marinotto, S. Righetto, G. Griffini, S. Turri, H. Akdas-Kilig, J.-L. Fillaut, A. Amar, A. Boucekkine and C. Katan, Dalt. Trans., 2016, 45, 1105211060.

K. Sénéchal-David, A. Hemeryck, N. Tancrez, L. Toupet, J. A. G. Williams, I. Ledoux, J. Zyss, A. Boucekkine, J.-P. Guégan, H. Le Bozec and O. Maury, J. Am. Chem. Soc., 2006, 128, 12243-12255.

A. Valore, E. Cariati, S. Righetto, D. Roberto, F. Tessore, R. Ugo, I. L. Fragalà, M. E. Fragalà, G. Malandrino, F. De Angelis, L. Belpassi, I. Ledoux-Rak, K. H. Thi and J. Zyss, J. Am. Chem. Soc., 2010, 132, 4966-4970.

A. Gulino, I. L. Fragalà, F. Lupo, G. Malandrino, A. Motta, A. Colombo, C. Dragonetti, S. Righetto, D. Roberto, R. Ugo, F. Demartin, I. Ledoux-Rak and A. Singh, Inorg. Chem., 2013, 52, 7550-7556.

E. Furet, K. Costuas, P. Rabiller and O. Maury, J. Am. Chem. Soc., 2008, 130, 2180-2183.

G.-L. Law, K.-L. Wong, K.-K. Lau, S. Lap, P. A. Tanner, F. Kuo and W.-T. Wong, J. Mater. Chem., 2010, 20, 4074.

J. W. Walton, R. Carr, N. H. Evans, A. M. Funk, A. M. Kenwright, D. Parker, D. S. Yufit, M. Botta, S. De Pinto and K.-L. Wong, Inorg. Chem., 2012, 51, 8042-8056.

H. Le Bozec, V. Guerchais, H. Akdas-Kilig, O. Maury, L. Ordronneau, A. Boucekkine, A. Singh, I. Ledoux and J. Zyss, Nonlinear Opt. Quantum Opt., 2012, 43, 187-196.

M. M. Ayhan, A. Singh, E. Jeanneau, V. Ahsen, J. Zyss, I. Ledoux-Rak, A. G. Gürek, C. Hirel, Y. Bretonnière and C. Andraud, Inorg. Chem., 2014, 53, 4359-4370.

C. Adamo and V. Barone, J. Chem. Phys., 1999, 110, 61586170.

M. J. Frisch, G. W. Trucks, H. B. Schlegel, G. E. Scuseria, M. A. Robb, J. R. Cheeseman, G. Scalmani, V. Barone, B. Mennucci and G. A. Petersson, Gaussian09, 2015. P. J. Hay and W. R. Wadt, J. Chem. Phys., 1985, 82, 299. M. Dolg, H. Stoll, H. Preuss and R. M. Pitzer, J. Phys. Chem., 1993, 97, 5852-5859.

V. Barone, M. Cossi and J. Tomasi, J. Chem. Phys., 1997, 107, 3210.

J. E. Rice and N. C. Handy, Int. J. Quantum Chem., 1992, 43, 91-118.

P. J. Stephens, F. J. Devlin, C. F. Chabalowski and M. J. 


\section{COMMUNICATION}

Frisch, J. Phys. Chem., 1994, 98, 11623-11627.

22

T. Yanai, D. P. Tew and N. C. Handy, Chem. Phys. Lett., 2004, 393, 51-57.

23 Y. Zhao and D. G. Truhlar, Theor. Chem. Acc., 2007, 120, 215-241.

24 J. Yang and M. Dolg, Theor. Chem. Acc., 2005, 113, 212224. 